\title{
Measured Supersonic Flame Properties: Heat-Release Patterns, Pressure Losses, Thermal Choking Limits
}

\author{
Youngbin Yoon,* Jeffrey M. Donbar, $\dagger$ Hwanil Huh, $\ddagger$ and James F. Driscoll§ \\ University of Michigan, Ann Arbor, Michigan 48109-2118
}

\begin{abstract}
Some general properties of a research-scale supersonic combustion device are reported and compared to a simple one-dimensional analysis of supersonic flow with heat addition and area change. The properties that were measured include the stagnation pressure losses because of combustion, the static pressure axial profiles, and the thermal choking limits; the heat-release pattern was inferred from these measurements. A simple combustor geometry was chosen that consists of a hydrogen-air turbulent jet flame that is stabilized along the axis of a supersonic (Mach 2.2) airflow within a diverging duct. It was found that the heat-release pattern (in kilowatts per centimeter of axial distance) is not uniform in space, but varies in a lognormal manner in the axial direction for the supersonic jet flame, which differs from the Gaussian pattern that characterizes a subsonic jet flame. The difference is attributed to earlier air entrainment and combustion caused by the supersonic coflowing air. It was found that it is possible to adequately estimate the measured stagnation pressure loss and the thermal choking limits using a one-dimensional analysis, if the measured lognormal shape of the heat release pattern is used. Measurements also quantify the wall divergence angle that is required to avoid thermal choking.
\end{abstract}

\section{Nomenclature}

$A \quad=$ area of supersonic combustor

$c_{P} \quad=$ heat capacity

$d_{F} \quad=$ inner diameter of fuel tube

$f \quad=$ mixture fraction

$L_{f} \quad=$ visible flame length

$M \quad=$ Mach number

$p, p_{0}=$ static, stagnation pressures

$Q=$ heat added per unit mass flow

$q_{F} \quad=$ heat added per unit mass flow, per unit length

$r \quad=$ radial coordinate

$T, T_{0}=$ static, stagnation temperatures

$\gamma \quad=$ ratio of specific heats

$\theta / 2=$ wall divergence half-angle

$\rho_{F}, \rho_{A}=$ density of fuel, air at fuel injection location

$\phi \quad=$ overall fuel-air equivalence ratio

\section{Introduction}

$\mathbf{T}$ HE way in which heat is released within a supersonic combustor plays an important role in the combustor design. As heat is released, the gas expands and occupies a larger volume, which affects the entrainment streamlines, flame lengths, ${ }^{1}$ flame stability, ${ }^{2}$ and supersonic mixing. ${ }^{3}$ Heat release also drives the local Mach number toward unity and increases the static pressure, ${ }^{4}$ which can result in increased wall heat transfer rates, shock-wave formation, ${ }^{5}$ and may lead to thermal choking. ${ }^{6}$ To quantify some of these effects, it was decided to study the fundamental case of an axisymmetric hydrogen-air turbulent jet flame stabilized on the axis of supersonic wind tunnel (Mach 2.2) with diverging sidewalls.

Received Feb. 21, 1995; revision received Oct. 10, 1995; accepted for publication Jan. 2, 1996. Copyright (C) 1996 by the American Institute of Aeronautics and Astronautics, Inc. All rights reserved.

*Postdoctoral Fellow, Department of Aerospace Engineering; currently at University of California, Davis, CA 95616. Member AIAA.

†USAF Palace Knight Research Assistant, Department of Aerospace Engineering. Member AIAA.

¥Graduate Student, Department of Aerospace Engineering. Member AIAA.

§Professor, Department of Aerospace Engineering. Associate Fellow AIAA.
In the present supersonic wind tunnel, no attempt was made to simulate the actual mass flow rates, stagnation pressures, and stagnation temperatures of realistic scramjet combustors. Instead, measurements were obtained that can be used to assess simple one-dimensional models as well as more complex twodimensional models ${ }^{7-10}$ of a generic supersonic combustion process. It is realized that realistic stagnation temperatures will create a high degree of dissociation as well as complex chemistry effects that cannot be modeled by simple one-dimensional models and are not fully simulated by the present experiment. However, the present results can be useful in the development of first-generation supersonic combustion models, which can later be modified to account for complex chemistry.

A critical piece of information that is required in one-dimensional models is the heat-release distribution $\mathrm{d} Q / \mathrm{d} x$ as a function of axial distance. The quantity $\mathrm{d} Q$ is the heat added per unit mass flow in the axial distance $\mathrm{d} x$. Compressible one-dimensional flow theory ${ }^{11}$ states that for a duct in which $\mathrm{d} Q / \mathrm{d} x$ and the area $A(x)$ are known, the following three equations predict the variation of the three unknowns: $M, p$, and $T$ :

$$
\begin{gathered}
\frac{\mathrm{d} M}{\mathrm{~d} x}=f_{1}(M) A^{-1}\left(\frac{\mathrm{d} A}{\mathrm{~d} x}\right)+f_{2}(M)\left(c_{p} T\right)^{-1}\left(\frac{\mathrm{d} Q}{\mathrm{~d} x}\right) \\
T^{-1} \frac{\mathrm{d} T}{\mathrm{~d} x}=f_{3}(M) A^{-1}\left(\frac{\mathrm{d} A}{\mathrm{~d} x}\right)+f_{4}(M)\left(c_{p} T\right)^{-1}\left(\frac{\mathrm{d} Q}{\mathrm{~d} x}\right) \\
p^{-1} \frac{\mathrm{d} p}{\mathrm{~d} x}=f_{5}(M) A^{-1}\left(\frac{\mathrm{d} A}{\mathrm{~d} x}\right)+f_{6}(M)\left(c_{p} T\right)^{-1}\left(\frac{\mathrm{d} Q}{\mathrm{~d} x}\right)
\end{gathered}
$$

where $f_{1}(M)$ is $-M\left[1+(\gamma-1) M^{2} / 2\right]\left(1-M^{2}\right)^{-1}, f_{2}(M)$ is $(M / 2)\left(1+\gamma M^{2}\right)\left(1-M^{2}\right)^{-1}, f_{3}(M)$ is $(\gamma-1) M^{2}\left(1-M^{2}\right)^{-1}$, $f_{4}(M)$ is $\left(1-\gamma M^{2}\right)\left(1-M^{2}\right)^{-1}, f_{5}(M)$ is $\gamma M^{2}\left(1-M^{2}\right)^{-1}$, and $f_{6}(M)$ is $-\gamma M^{2}\left(1-M^{2}\right)^{-1}$.

To calculate the unknowns $M, p$, and $T$, the shape of the heat-release distribution curve $(\mathrm{d} Q / \mathrm{d} x$ as a function of $x)$ must be known. The area under this curve $(Q)$ is known for a given experiment, since $Q$, the total heat released per kilogram of gas mixture, equals the product of the known fuel mass flow rate and the lower heating value of the fuel, divided by the sum of the fuel and air mass flow rates. The heat-release curve is normalized using the flame length; values of the lengths of the present supersonic flames were reported in Ref. 2. 
One goal of the present study is to determine the shape of heat-release distribution curve $\mathrm{d} Q / \mathrm{d} x$ from measurements in the supersonic combustor. To do so, the inverse of the previous procedure is performed: instead of assuming that $\mathrm{d} Q / \mathrm{d} x$ is given, we treat $\mathrm{d} Q / \mathrm{d} x$ as an unknown and use the measurement of the static pressure $p(x)$ as input to the calculations. Thus, Eqs. (1-3) represent three equations for three unknowns: $\mathrm{d} Q / \mathrm{d} x, M$, and $T$, given that the area $A(x)$ and measured values of $p(x)$ are known.

\section{Experimental Configuration}

Figure 1 shows a schematic diagram of the experiment. Previous papers ${ }^{1.2}$ provide additional details about the present supersonic flames, including flame lengths and the stability limits, whereas a general discussion of supersonic combustion is provided by Hussaini et al. ${ }^{12}$ Air is accelerated to Mach 2.2 in a two-dimensional converging-diverging nozzle that was designed using the method of characteristics. Thermal choking occurred in all cases when a constant area combustor section was used; therefore, two of the combustor sidewalls are parallel for optical access, while the other two sidewalls have a divergence half-angle $\Theta / 2$ that was set to 1 and $4 \mathrm{deg}$. Combustor dimensions at the fuel injection plane are 5.7 by 4.06 $\mathrm{cm}$. The $55-\mathrm{cm}$-long diverging section is followed by a $50-$ $\mathrm{cm}$-long constant area combustor section that is $11 \mathrm{~cm}$ in width. The flames studied varied in length from 20 to $95 \mathrm{~cm}$. All components are stainless steel and the eight windows are quartz glass. The diffuser wall is water cooled. The stagnation temperature of the airflow was typically $294 \mathrm{~K}$.

The fuel injector is a stainless-steel tube with an i.d. $d_{F}$ of $0.70 \mathrm{~cm}$. The o.d. of the bluff-body shown in Fig. 1 is 2.54 $\mathrm{cm}$. The bluff-body fuel injector does introduce a significant area discontinuity where the flow cannot realistically be compared to a one-dimensional analysis. However, it was found that the bluff-body geometry was necessary to stabilize the supersonic flames ${ }^{1}$ and that downstream of this abrupt area discontinuity the area changes gradually such that comparisons

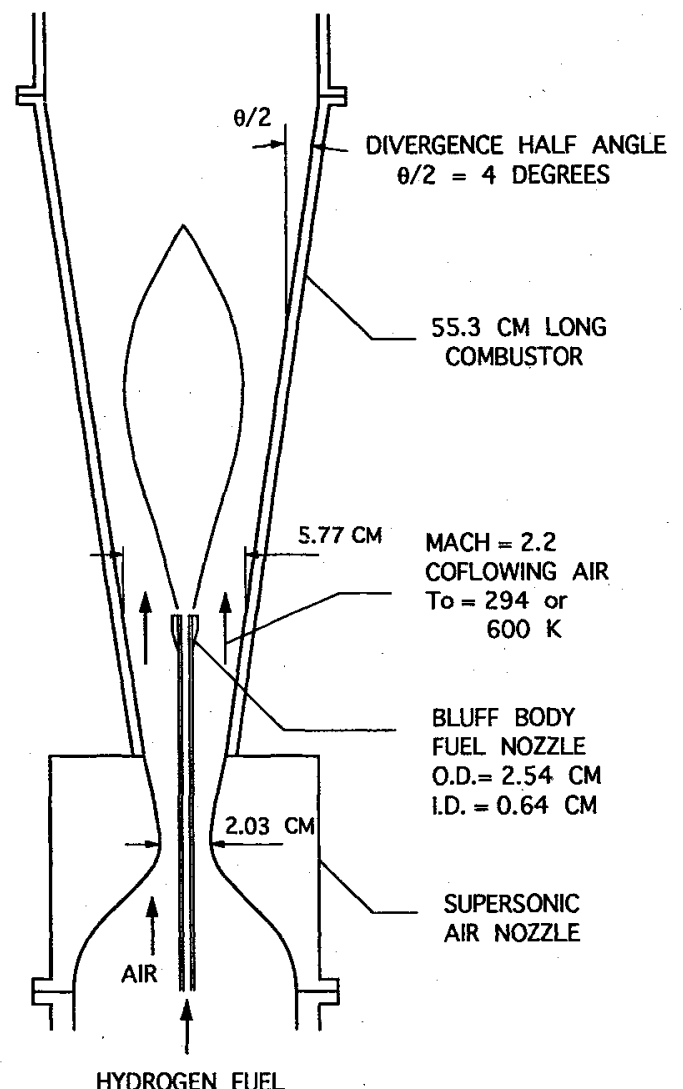

Fig. 1 Schematic diagram of the supersonic combustor.

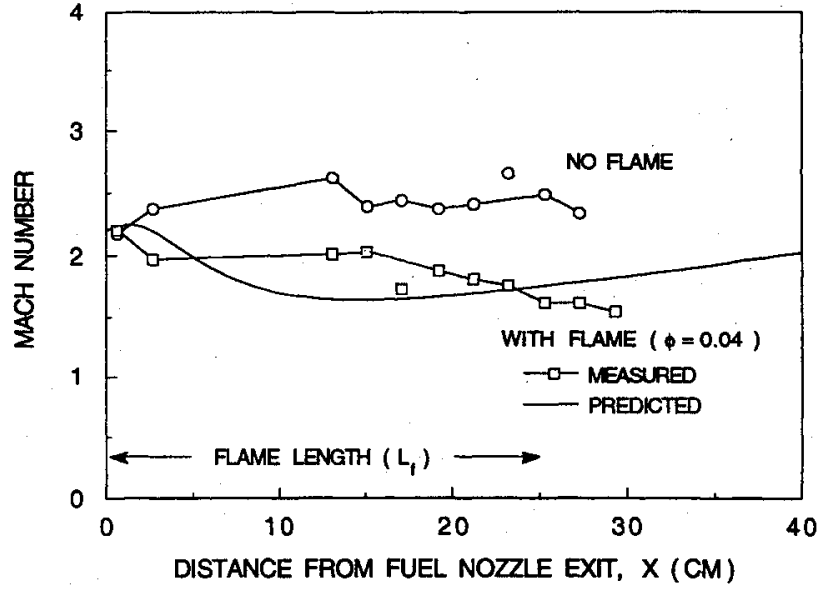

Fig. 2 Measured Mach number of the coflowing airstream. Values deduced from a pitot probe inserted in the coflowing airstream and from wall static pressure. $P_{0 A}=6.44 \mathrm{~atm}, T_{0 A}=294 \mathrm{~K}, \phi=$ $0.04, \theta / 2=4 \mathrm{deg}$.

to a one-dimensional analysis are useful. The hydrogen is injected at a sonic velocity of $1191 \mathrm{~m} / \mathrm{s}$ for the stagnation temperature of $294 \mathrm{~K}$. Only sonic fuel injection was considered. The fuel tube has a length of $94 d_{F}$, and so the fuel velocity profile can be assumed to correspond to that of fully developed turbulent pipe flow. The fuel and the air mass flow rates are monitored using calibrated choked orifices. The overall equivalence ratio $\phi$ is determined from the known flow rates of fuel and air. The flame is ignited by first inserting a torch into the combustor while the air velocity is subsonic; the fuel flow is initiated and the torch is removed, then the air velocity is carefully increased into the supersonic range.

The Mach number in the test section was measured by inserting a pitot probe in the airflow that surrounds the flame and by recording the static pressure at various pressure taps located in the sidewall. Some results are shown in Fig. 2. With no flame, the Mach number increases somewhat because of the wall divergence, as expected. With the flame, the Mach number does decrease in the axial direction, but some variations in Mach number are unavoidable in the present experiment. It is not possible to optimize the wall divergence angle each time the fuel flow rate is varied; each change in the fuel flow rate causes complex, interrelated changes in the following parameters that affect the local Mach number: the flame length, the amount of heat released, and the flowfield blockage caused by the flame. Therefore, only two wall divergence half-angles of 4 and $1 \mathrm{deg}$ were considered. The pitot pressure profiles were nearly uniform in the supersonic airflow between the flame and the wall boundary layer. It could not be determined if the wall boundary layer had separated, because the rugged pitot probe was not small enough to accurately survey the wall boundary layer.

\section{Results}

Static Pressure Increase and Heat Release Pattern for Supersonic Combustion

Figure 3 shows some predicted static pressure profiles [using Eqs. (1-3)] for initial conditions and area changes that correspond to the experiment, and Fig. 4 shows some measured static pressure profiles. Figure 3 shows that with no flame $(\phi$ $=0$ ), static pressure decreases, and Mach number increases in the axial direction because of the wall divergence. Increasing the total heat added (which is proportional to both the fuel flow rate and $\phi$ ), drives the Mach number to unity. Near the flame base, an abrupt increase in static pressure is predicted, as seen in Fig. 3, followed by a decay in the pressure downstream where the effect of area increase overcomes the effect 


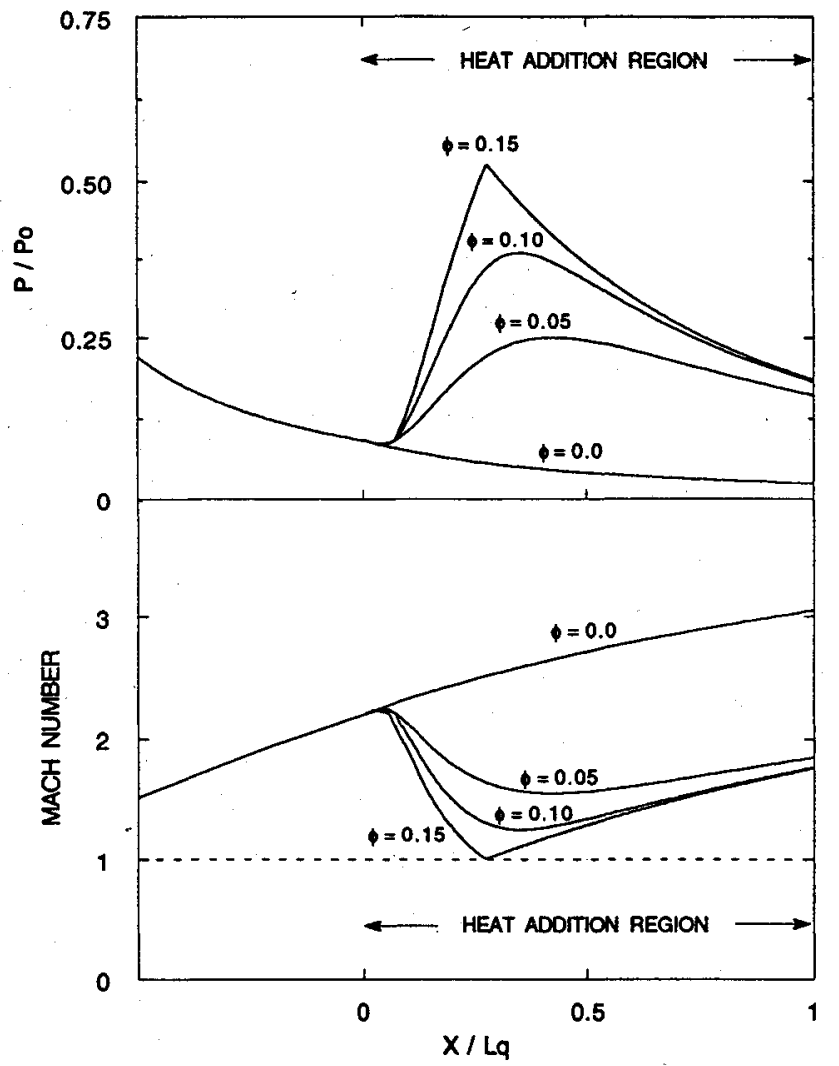

Fig. 3 Calculated static pressures and Mach numbers using onedimensional analysis [Eqs. (1-3)]. At $x=0, M_{A}=2.2, P_{0 A}=6.44$ atm, $T_{0 A}=294 \mathrm{~K}, \theta / 2=4 \mathrm{deg}$.

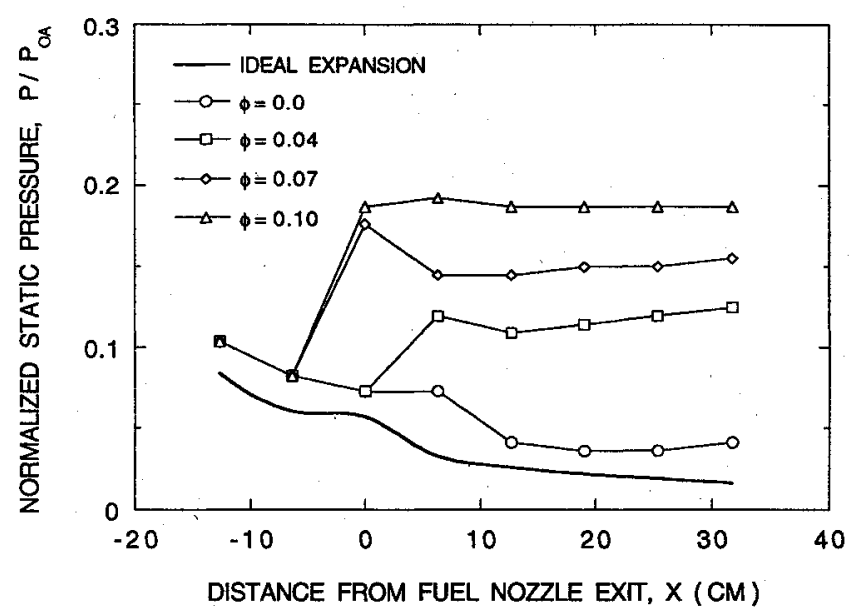

Fig. 4 Wall static pressures measured for various supersonic flames with wall divergence half-angle $=4 \mathrm{deg}$. Conditions same as Fig. 3: $M_{A}=2.2, P_{0 A}=6.44 \mathrm{~atm}, T_{0 A}=294 \mathrm{~K}, \theta / 2=4 \mathrm{deg}$.

of heat addition. Thermal choking is predicted to occur for a $\phi$ of 0.15 in this case.

The measured values of wall static pressure, which are shown in Figs. 4 and 5, are observed to follow the same general trends that were predicted in Fig. 3. Pressures reported in Fig. 4 correspond to a wall divergence half-angle of $4 \mathrm{deg}$, whereas the values in Fig. 5 correspond to a half-angle of 1 deg. The lowest curve in Fig. 4 represents the case of ideal isentropic expansion; there is a small pressure rise in this curve near $x=0$ that is caused by the area change associated with the bluff-body fuel injector geometry. This small pressure rise near $x=0$ also is observed in some of the measured pressure curves. The measured static pressures with no heat addition $(\phi=0)$ are larger than the ideal values because of possible

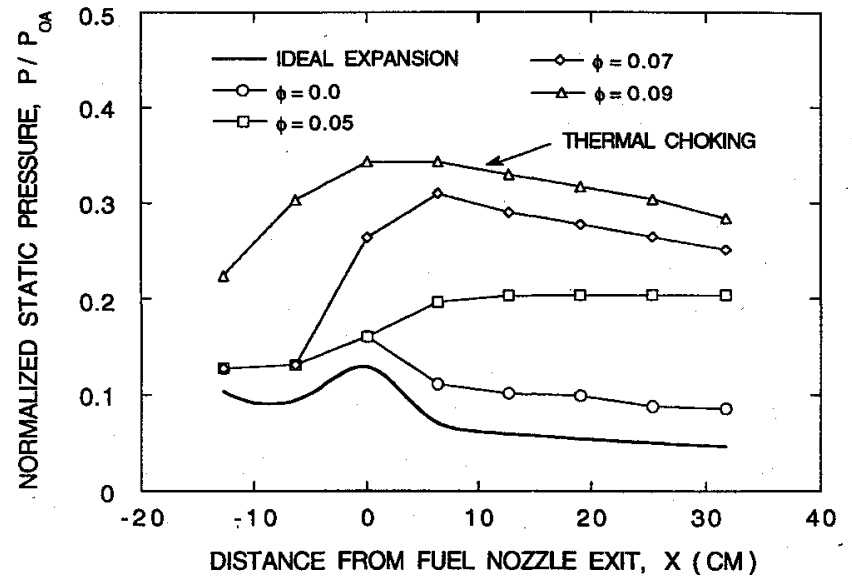

Fig. 5 Wall static pressures measured for various supersonic flames with wall divergence half-angle $=1 \mathrm{deg} . M_{A}=2.2, P_{0 A}=$ $5.08 \mathrm{~atm}, T_{0 A}=294 \mathrm{~K}$.

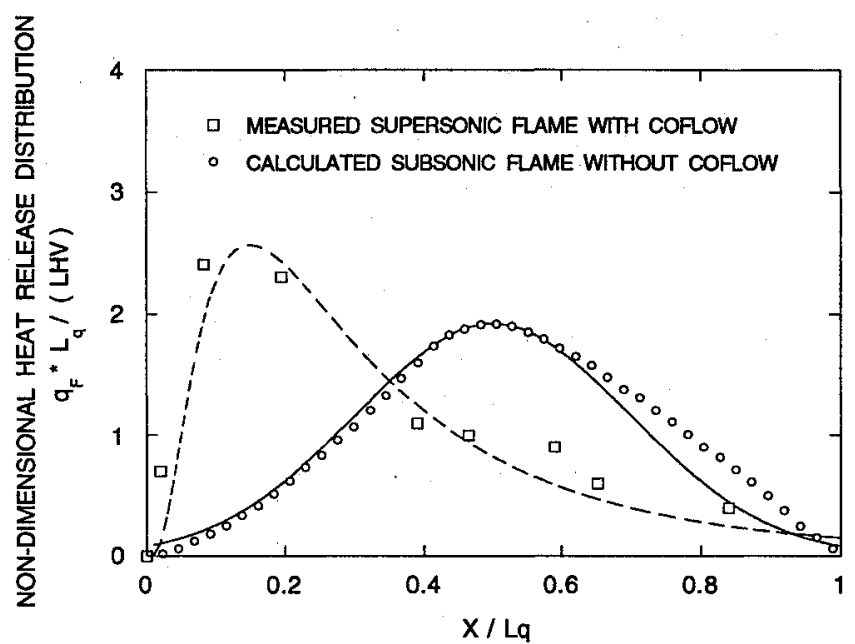

Fig. 6 Measured heat-release distribution of the supersonic flame compared to a calculated distribution for a self-similar subsonic flame. $q_{F}=\mathrm{kJ}$ of heat released per centimeter in the axial direction per kilogram of fuel consumed. Area under each curve is unity. Dashed line = lognormal distribution $(A=5.15, \mu=-1.9, \sigma=$ $0.8)$. Solid line $=$ Gaussian distribution $\left(A^{\prime}=1.01, \mu^{\prime}=0.5, \sigma^{\prime}=\right.$ $0.2)$. $\mathrm{LHV}=119,000 \mathrm{~kJ} / \mathrm{kg}$ fuel for hydrogen.

sidewall boundary-layer effects, including some separation and/or corner flow disturbances because of the rectangular cross section of the sidewalls.

The heat-release distribution for the supersonic jet flame is shown in Fig. 6. Static pressure measurements and the known combustor area $A(x)$ were input into Eqs. $(1-3)$ to deduce $\mathrm{d} Q /$ $\mathrm{d} x$, which is the heat added per mass of fuel and air. Since $\mathrm{d} Q / \mathrm{d} x$ depends on the dimensions of the combustor, a more general quantity is defined and denoted as the nondimensional heat-release parameter $Q^{*}$, which is $q_{F} L_{f} /$ lower heating value for hydrogen (LHV). The quantity $q_{F}$ is the heat added per unit length, per unit mass of the fuel alone; $L_{f}$ is the flame length that was measured for the present flames and was reported elsewhere $^{2}$; LHV is $119,000 \mathrm{~kJ} / \mathrm{kg}$. Because of this choice of normalization, the area under each curve in Fig. 6 must be unity. Furthermore, the profile of $Q^{*}$ in Fig. 6 is independent of combustor dimensions and flow rates, but is expected to be affected by certain nondimensional parameters such as the ratio of fuel-to-air injection velocities, which affect the shear layer and the mixing process.

Figure 6 shows that $Q^{*}$ is adequately represented by a lognormal curve (that is truncated at $x / L_{f}=1$ ) for the supersonic jet flame. The shape of the lognormal curve is such that much 
of the heat release occurs in the upstream region of the supersonic flame. The best-fit lognormal curve is given by

$Q^{*}=A \sigma^{-1}\left(x / L_{f}\right)^{-1}(2 \pi)^{-1 / 2} \exp \left\{-\left[\ell n\left(x / L_{f}\right)-\mu\right]^{2} /\left(2 \sigma^{2}\right)\right\}$

with constants $A, \mu$, and $\sigma$ equal to $5.15,-1.9$, and 0.8 , respectively. For comparison, a typical $Q^{*}$ for a subsonic jet flame was estimated and is shown in Fig. 6. The subsonic flame calculation was performed by using laminar flamelet concepts: local heat release was calculated as a function of $f$ for a counterflow flame at low strain rates, a value of the local heat release is assigned to each contour of mean mixture fraction in the jet, and the contours of mean $f$ in a turbulent jet flame with no coflow are given by ${ }^{13}$

$$
f(r, x)=5.2\left(\rho_{F} / \rho_{A}\right)^{1 / 2}\left(d_{F} / x\right)\left[1+25(r / x)^{2}\right]^{-2}
$$

The heat release per length of the flame is calculated by integrating the local heat-release values over all radial locations. The resulting estimate of the subsonic heat-release distribution is seen in Fig. 6 to be best-fit by a Gaussian profile, as given by

$$
Q^{*}=A^{\prime} \sigma^{\prime-1}(2 \pi)^{-1 / 2} \exp \left\{-\left[\left(x / L_{f}\right)-\mu^{\prime}\right]^{2} /\left(2 \sigma^{\prime 2}\right)\right\}
$$

The constants $A^{\prime}, \sigma^{\prime}$, and $\mu^{\prime}$ are $1.01,0.2$, and 0.5 , respectively. The Gaussian heat-release pattern given by Eq. (6) is a theoretical result and has not been measured previously; however, it is based on the mixture fraction profile given by Eq. (5), which has been documented in several experimental studies. $^{14}$

Comparison of the heat-release patterns in Fig. 6 indicates that the supersonic flame displays larger heat release in the upstream portion of the jet, whereas the subsonic flame is predicted to release heat farther downstream. This difference is believed to be from rapid air entrainment in the supersonic case because of the high-speed coflowing air; in a subsonic jet flame the air entrained per unit length is constant.

\section{Stagnation Pressure Losses and Thermal Choking}

The stagnation pressure losses in the supersonic combustor are plotted in Fig. 7. A pitot probe was used to measure pitot pressure in the airstream that surrounds the flame; pitot pressures and the wall static pressures were used to deduce the local stagnation pressure. For the selected conditions, the stagnation pressure decreased to approximately one-half its original value. The predicted value of stagnation pressure at the end of the heat addition region was calculated using Eqs. (13 ) and the assumption that the heat-release pattern has a log-

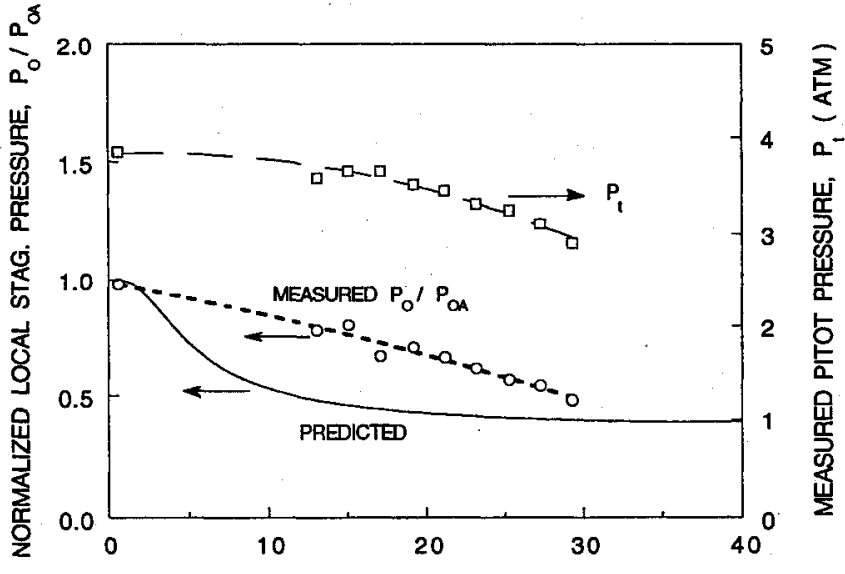

DISTANCE FROM FUEL NOZZLE EXIT, $x$ (CM)

Fig. 7 Stagnation pressures in the supersonic airflow surrounding the flame, deduced from pitot and wall pressures. $M_{A}=\mathbf{2 . 2}$, $P_{0 A}=6.44 \mathrm{~atm}, T_{0 A}=294 \mathrm{~K}, \theta / 2=4 \mathrm{deg}, \phi=0.04$. normal shape, as shown in Fig. 6. The results shown in Fig. 6 indicate that there is reasonable agreement between the predicted and measured overall stagnation pressure loss at the end of the flame $(x=30 \mathrm{~cm})$; however, there is poor agreement at locations within the heat addition zone.

It is encouraging that the overall stagnation pressure loss (at $x=30 \mathrm{~cm}$ in Fig. 7) can be reasonably predicted, as shown in Fig. 7, by combining Eqs. (1-3), the known total amount of $Q$, the measured fiame lengths in Fig. 8, and the known shape of the heat-release pattern in Fig. 6. Some differences between predictions and measurements are expected because the flow is not truly one dimensional. The flame creates radial gradients in the gas temperature and density, and the rectangular windtunnel cross section may promote some complex corner flows. Another source of error is the assumption that combustion is $100 \%$ complete in calculating the total heat that is released per second in the analysis. This total heat-release value is computed using the lower heating value of hydrogen and the known mass flow rate of fuel. It is not known what fraction of the fuel remains unburned; however, the flame is stable and has the shape of a typical jet diffusion flame in which the combustion is typically more that $97 \%$ complete.

Two criteria were used to identify thermal choking in the present experiment: choking occurs if the static pressure rises suddenly in the region that is upstream of the flame $(x<0)$, which indicates that a shock wave has moved upstream from the diffuser to the supersonic nozzle; choking also is identified from the schlieren images that are shown later as the condition when Mach waves (which indicate that the flow is supersonic), disappear downstream of the supersonic nozzle. The upper curve in Fig. 5 represents pressure data that indicate that thermal choking occurs when the overall equivalence ratio exceeds 0.09 for a 1-deg wall divergence half-angle. The two leftmost data points on that curve indicate that static pressure has risen upstream of the fuel injection location, where there is no heat addition. For equivalence ratios of 0.07 and 0.05 , the pressures upstream of the fuel injection location remain equal to the value for no combustion, indicating that thermal choking does not occur for those conditions.

Schlieren photographs of the thermal choking process appear in Figs. 9 and 10 for wall divergence angles of 1 and 4 deg, respectively. Under normal supersonic conditions, Mach waves appear in the photographs as diagonal lines because of tiny imperfections in the wall surface. As the fuel flow rate is increased to the thermal choking limit, shock waves are expected to pass back through the combustor and into the nozzle, causing the combustor to abruptly become subsonic, which causes any Mach waves to disappear. For the conditions of Fig. 9, the Mach waves abruptly disappear when the overall equivalence ratio reaches 0.09 . This is the same value of $\phi$ at

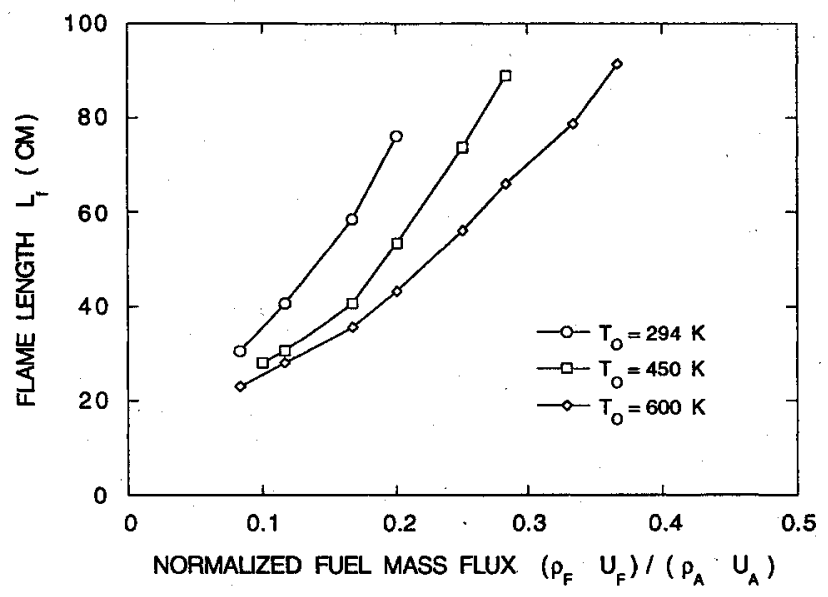

Fig. 8 Some measured supersonic flame lengths used to determine the heat-release distribution. $P_{0 A}=6.44 \mathrm{~atm}, \theta / 2=4 \mathrm{deg}$. 
$\theta / 2=1^{\circ}$

Mach wave indicated supersonic flow $M=2.0$ $\mathrm{x}=\mathrm{O} \longrightarrow$
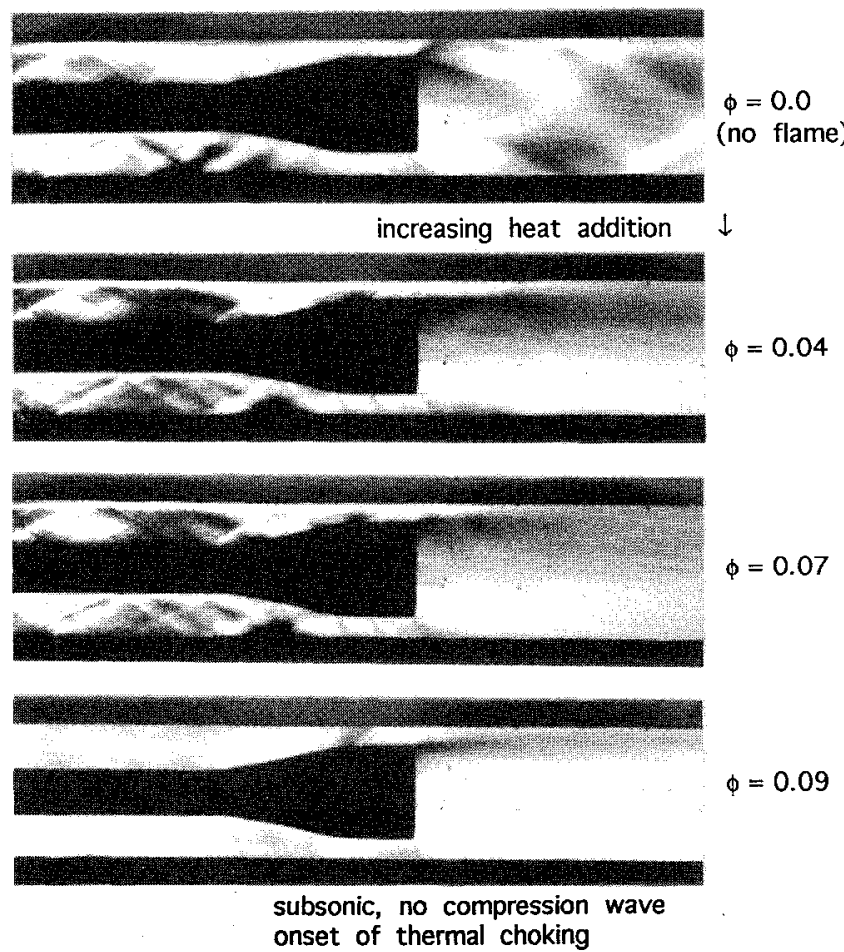

Fig. 9 Schlieren photographs of thermal choking for wall divergence $\theta / 2=1 \mathrm{deg} . M_{A}=2.2, P_{0 A}=5.08 \mathrm{~atm}, T_{0 A}=294 \mathrm{~K}$. Thermal choking occurs in the lowest photograph $(\phi=0.09)$ because the Mach waves have disappeared, indicating that a shock wave has passed back into the nozzle and the combustor is subsonic.

which thermal choking was identified to occur, based on the increase of static pressure upstream of the flame $(x<0)$ in Fig. 5. The onset of thermal choking also is identified by a significant increase in the acoustic noise and visible oscillations of the central fuel tube. For an increased wall divergence angle of $4 \mathrm{deg}$, Fig. 10 shows that an increased value of $\phi=$ 0.15 is required to cause a disappearance of the Mach waves and the onset of thermal choking.

The measured thermal choking limits are compared to predictions in Fig. 11. The predicted curve in Fig. 11 is determined by solving Eqs. (1-3) for various values of $\phi$, assuming that the shape of the heat-release distribution is lognormal, as was demonstrated previously. A set of Mach number curves similar to Fig. 3b are generated, and choking is predicted to occur when the Mach number at the end of the heat addition zone decreases to unity. The measured values of $\phi_{\max }$ in Fig. 11 are based on both the schlieren images and the pressure data. The reasonable agreement between measurements and calculations observed in Fig. 11 indicates that one-dimensional analysis can be used to estimate the onset of thermal choking if a realistic lognormal shape of the heat-release distribution curve is used in the calculation.

The presence of shock waves in the combustion region cannot be observed in the schlieren images in Figs. 9 and 10. In the upper image of each figure some weak Mach waves are observed for the case of no combustion; these waves are because of gradual changes in the flow geometry as well as the abrupt change at the corner of the bluff-body fuel injector. In the cases with combustion (the lower three images in Figs. 9 and 10), the flame creates.a large radial density gradient such that the upper half of the flame appears dark and the lower half appears white. These radial gradients obscure any shock waves present; for example, the sonic hydrogen fuel jet should produce some waves just downstream of the fuel injector, but

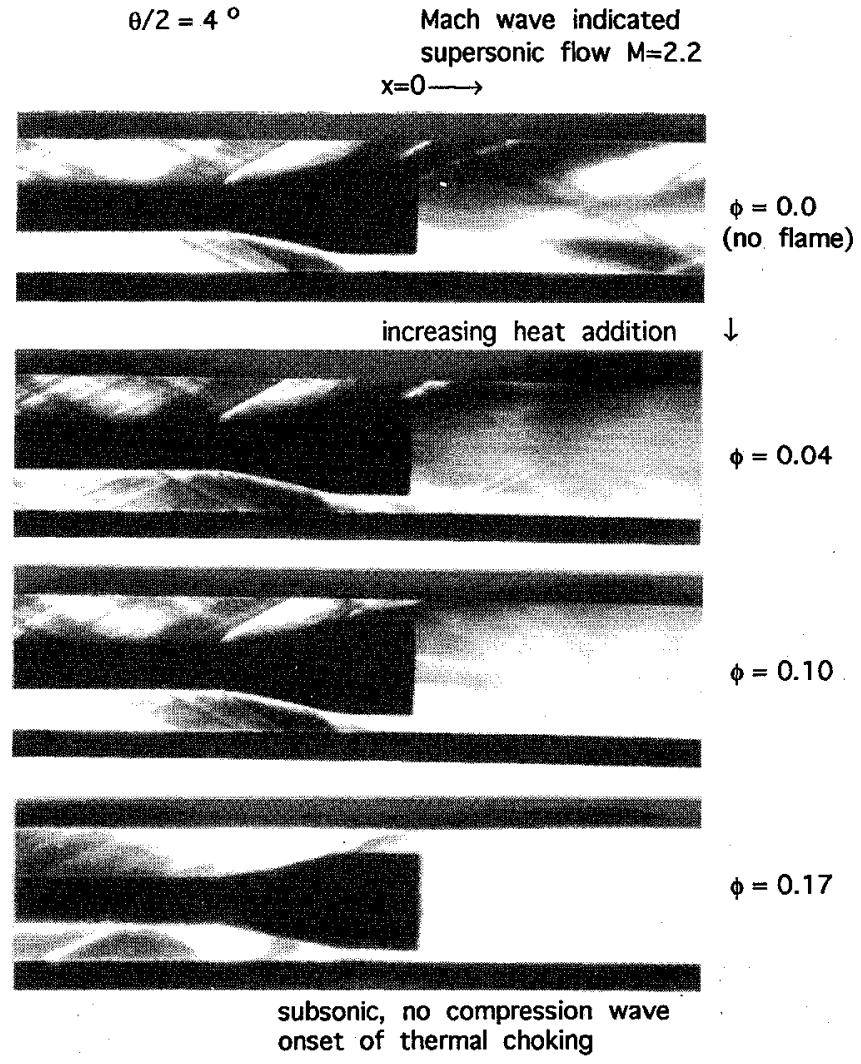

Fig. 10 Schlieren photographs of thermal choking for wall divergence half-angle $\theta / 2=4 \mathrm{deg} . M_{A}=2.2, P_{0 A}=6.44 \mathrm{~atm}, T_{0 A}=$ $294 \mathrm{~K}$. Thermal choking occurs in the lowest photograph $(\phi=$ 0.17).

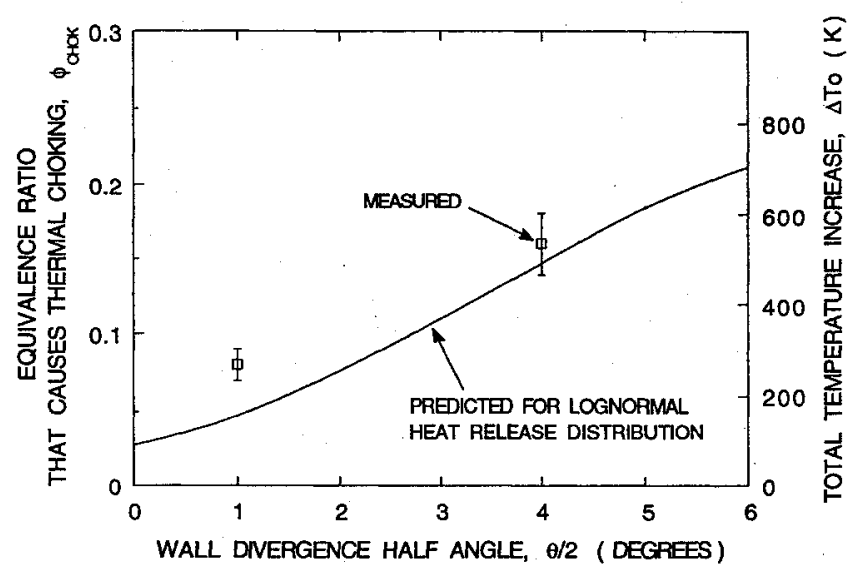

Fig. 11 Measured thermal choking limits compared to the predictions of the one-dimensional analysis [Eqs. $(1-3)] . M_{A}=\mathbf{2 . 2}$, $P_{\mathrm{BA}}=6.44 \mathrm{~atm}, T_{\mathrm{BA}}=294 \mathrm{~K}$.

none is seen. A future study is planned to use improved methods to visualize the flow geometry and wave patterns in the flames.

\section{Conclusions}

1) The heat-release distribution within a supersonic jet flame can be approximated by a lognormal curve, as inferred from the measured rate of rise of the wall static pressure. The maximum heat release occurs in the upstream regions of the flame, which differs from calculations for a subsonic flame, in which maximum heat release occurs farther downstream. The earlier heat release in the supersonic case is believed to be because of the rapid entrainment of air caused by the high-speed coflowing airstream. 
2) The stagnation pressure losses because of the flame were measured to be large (up to one-half of the initial stagnation pressure), and the total loss tends to agree with that calculated using a one-dimensional analysis, providing that the shape of the heat-release distribution used in the calculation is lognormal.

3) The degree of wall divergence that is required to avoid thermal choking was measured and agrees with one-dimensional analysis, providing that the shape of the heat release distribution used in the calculation is lognormal.

\section{References}

${ }^{1}$ Yoon, Y., Donbar, J. M., and Driscoll, J. F., 'Blowout Stability Limits of a Hydrogen Jet Flame in a Supersonic, Heated, Coflowing Air Stream," Combustion Science Technology, Vol. 97, 1994, pp. $137-156$

${ }^{2}$ Driscoll, J. F., Huh, H., Yoon, Y., and Donbar, J. M., “Measured Lengths of Supersonic Hydrogen-Air Jet Flames-Compared to Subsonic Flame Lengths and Analysis," Combustion and Flame (to be published).

${ }^{3}$ Miller, M. F., Island, T. C., Yip, B., Bowman, C. T., Mungal, M. G., and Hanson, R. K., "An Experimental Study of the Structure of a Compressible, Reacting Mixing Layer," AIAA Paper 93-0354, Jan. 1993.

${ }^{4}$ Issac, J. J., and Cookson, R. A., "Combustion Generated Heat Addition to a Ducted Supersonic Stream," Acta Astronautica, Vol. 6,
1979, pp. 511-539.

${ }^{5}$ Billig, F. S., "Combustion Processes in Supersonic Flow," Journal of Propulsion and Power, Vol. 4, No. 3, 1988, pp. 209-216.

${ }^{6}$ Billig, F. S., and Dugger, G. L., "Interaction of Shock Waves and Heat Addition in the Design of Supersonic Combustors," 12th Symposium (International) on Combustion, The Combustion Inst., Pittsburgh, PA, 1968, p. 1125.

'Villasenor, R., Chen, J. Y., and Pitz, R. W., "Modelling Ideally Expanded Supersonic Turbulent Jet Flows with Nonpremixed $\mathrm{H}_{2}$-Air Combustion," AIAA Journal, Vol. 30, No. 2, 1992, pp. 395-402.

${ }^{8}$ Eklund, D. R., Drummond, J. P., and Hassan, H. A., "Calculation of Supersonic Turbulent Reacting Coaxial Jets," AIAA Journal, Vol. 28, No. 9, 1990, pp. 1633-1641.

${ }^{9}$ Zheng, L. L., and Bray, K. N. C., " "The Application of New Combustion and Turbulence Models to $\mathrm{H}_{2}$-Air Nonpremixed Supersonic Combustion," Combustion and Flame, Vol. 99, 1994, pp. 440-449.

${ }^{10}$ Mohieldin, T. O., Tiwari, S. N., and Chandrasekhar, R., "Numerical Investigation of Radiation and Turbulence Interactions in Supersonically Expanded Hydrogen-Air Diffusion Flames," AIAA Paper 95-0135, Jan. 1995.

${ }^{11}$ Shapiro, A. T., Dynamics and Thermodynamics of Compressible Fluid Flow, Ronald, New York, 1953.

${ }^{12}$ Hussaini, M. Y., Kumar, A., and Voight, R. G., Major Research Topics in Combustion, Springer-Verlag, New York, 1992.

${ }^{13}$ Peters, N., and Williams, F. A., AIAA Journal, Vol. 21, No. 3, 1983 , pp. 423-429.

${ }^{14}$ Pitts, W. M., and Kashiwagi, T., Journal of Fluid Mechanics, Vol. 141,1984 , pp. $391-429$.

\section{Tactical Missile Propulsion}

G.E. Jensen and David: W. Netzer, editors

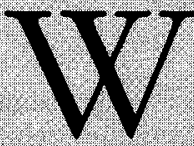

ith contributions from the leading researchers and scientists in the field, this new volume is a compendium of the latest advances in tactical missile propulsion. The objectives of the book are to provide today's designer with a summary of the advances in potential propulsion systems as well as provide a discussion of major design and selection considerations. Authors were chosen for their demonstrated knowledge of and excellence in their respective fields to ensure a complete and up-to-date summary of the latest research and developments.

\section{CONIENTS:}

Design Concepts and Propulsion Definition • Liquid Rockets • Solid Rocket Motor Design • Solid Propellant Grain Struetural Design and Service IIfe Analysis • Solid Rocket Nozzle Design ? Solid Rodket Case Design • Solid Rocket Plumes • Insensitive Munitions for Solid Rockets $\bullet$ Gas Turbines - Liquid Fueled Ramets * Ducted Rockets - Solid Fueled Ramjets - High Mach Number Applications

1995. $650 \mathrm{pp}$, Illus, Hardback

ISBN $1-563+7-118-3$

AIAA Members $\$ 89.95$

List Price $\$ 104.95$

Order \#: V-170(945)

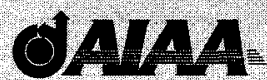

American Institute of Aeronautic and Astronautics Publications Custemer Service, 9 lay Gould CL, PO Box 753 Walor r WD 20604 Fax 30184300159 Phone $18001682-2422$ 8 an, -5 pin. Eastem
Sales Tax CA and BC residents add apolicable sales tax For shipbing and handitho ad 044.75 fo $1-4$ books (call tor rates for higher quantilies) Orders under $\$ 100.00$ nuss be prepaid. Foreign orders must be prepalt and wed lde a $\$ 2000$ gesta suratge please alow 4 weeks for delivery Prices a e subecl to change without notiee. Retums wil be accepted within 30 days. Non-U/S residents are esponsible for payment of any taxes required by their government. 